\title{
Manual Gym Air Conditioner Spin Bike Operated Air Conditioner
}

\author{
Niharigha Periyasamy, \\ Department of Mechanical Engineering, \\ Loyola-ICAM College of Engineering and Technology \\ (LICET), Chennai, India
}

\author{
M. Karthi \\ Assistant Professor, \\ Department of Mechanical Engineering, Loyola-ICAM \\ College of Engineering and Technology (LICET), \\ Chennai, India
}

\begin{abstract}
Energy is the need of the hour with depleting non renewable energy sources. In urban society with increasing demand of energy, there ought to be some new modern way to harness energy in order to match up the rising demands. Life in the city is fast and people are really concerned about their health, as a result of which we find 2 out of 10 people hit the gym on a regular basis. In addition to the cascading number of gyms in the city , there are gyming equipments that can be installed and used at home. Spin Bike is one of the most preferred and effective equipment.

Human beings have two contrasting needs, one is to make the society energy efficient and another is to burn their fat by spending a lot of energy. The energy wasted hours together in the gym is used to run an air conditioner using various mechanical setup by complete manual operations. Henceforth energy can be wisely recycled. Complete mechanical operation of an air conditioner makes it highly reliable, as air conditioner is one of the components that uses maximum energy during high operating hours. Specially designed gear arrangements, staging of gears, chain drive and flywheels are used to get the required output using simple pedalling motion at a comfortable pace.
\end{abstract}

Keywords:- Pedalling motion; Gymmers; energy conservation;air conditioner compressor rpm; constant output; less effort.

\section{INTRODUCTION}

Are we alone in this universe? The very first question that we should be addressing before the start of the paper is, what are the conditions that are necessary for life to exist in this world. As per the astronomy department of Ohio state university we summarize that the three basic requirements of life are Energy, complex chemistry and benign environments. So energy is the first and most important thing to survive, but the most important problem that is encountered with energy is the depleting sources of energy. The need of the hour for now is that we need to find an alternative non renewable source of energy to meet the increasing demand of the growing population. For the various researches that are done in various non renewable sources,can be summed up to and focussed to the places where energy is wasted. - There are around 24,000 gyms and studios in the country, out of which $95 \%$ are organised outlets and 5\% are unorganised," said Neha Motwani, co-founder at Fitternity, a web aggregator for fitness outlets. This pulled my attention deeply, as we find that almost 27 percent of the complete population of India hit the gym on a regular basis. We find that the amount of energy wasted in the gym by the gymmers can be harnessed in an effective way by the use of a machine that can use this unused energy. So this spark of idea led to the manifestation of the project Manual Gym Air Conditioner.
Manual gym air conditioner is basically use of the manual cycling power from the Spin Bike to run an AC by using various stages of chain drives and a flywheel for a stable output to the compressor. So this project has a dual advantage of reducing the energy spent by utilizing the energy that is wasted in the gym during exercising. force, the oil which is taken in between the flapper valve and suction flange cover assembly, should not be released throughout the dwell time.

\section{LITERATURE SURVEY}

The main problems that were identified in the similar kind of research papers are as follows: Energy Generating Gymnasiums Machines for Renewable, Sustainable and Green Energy-M. Musharraf, Ifrah Saleem, Dr. Farhat Iqbal pISSN:2395-0072

- Use of electronic and electrical components make it non reliable

- Steady flow of current is not guaranteed

- Cost of construction on an existing gym is more

- Utilizing the stored energy involves additional setup.

In order to address the above problems the new product is made

\section{A) Problem Definition}

\section{METHODOLOGY}

- Any human being has two contrasting needs, one is to make the society energy efficient and another is to burn their fat by spending a lot of energy. - So to utilize the spent energy in the gym we manifest this project.

B) Objective:

To utilize the energy spent in the gym by cycling action (Spin Bike) to run an air conditioner.

\section{Design Methodology}

The basic methodology that is followed in order to produce energy to run an Air conditioner is as follows: 1)Firstly we select an air conditioner for test purposes which will be suitable to get the required amount of energy. The specifications of AC that is selected is as follows:

\section{Type of AC : LG 1 Ton 2 Star LWA3BP2A Window AC}

Air circulation: $350 \mathrm{cfm}$

Dimensions: 600 x 380 x $560 \mathrm{~mm}$

Compressor rpm: 1800-3600 rpm(No load condition) 1750-3450 rpm(Under load condition) 
2) Secondly we select the gym equipment as spin bike, the specifications of Spin Bike is as follows:

Pedalling force for Spin bike:135N

Drive used: Chain drive ( Rolon chain)

3)Thirdly we calculate the rise in rpm from the pedalling speed of the Spin Bike for a normal human being to the rotating speed of the compressor to run the Air conditioner.

The rise in rpm was calculated to be from $80 \mathrm{rpm}$ (which is the minimum rpm from pedalling) to $3600 \mathrm{rpm}$.

4) Fourthly the drive system to cater the rpm rise is selected to be Chain drive and the teeth number and placements was finalised with the following calculations:

\begin{tabular}{|l|l|}
\hline $\mathrm{N} 1=80 \mathrm{rpm}$ & $\mathrm{T} 1=20 \mathrm{D} 1=600 \mathrm{~mm}$ \\
$\mathrm{~N} 2=160 \mathrm{rpm}$ & $\mathrm{T} 2=40 \mathrm{R} 1=0.3 \mathrm{~m}$ \\
\hline
\end{tabular}

Pitch of chain:

$0.3=(\mathrm{p} / 2) \operatorname{cosec}(180 / \mathrm{T} 2)=>3.196 \mathrm{p}=0.3$

$\mathrm{x}=\mathrm{mp}($ centre distance $)$

$\mathrm{m}=\mathrm{x} / \mathrm{p}=85.287$ (module)

Multiplying factor:

$\mathrm{k}=((\mathrm{T} 1+\mathrm{T} 2) / 2)+2 \mathrm{~m}+[\operatorname{cosec}(180 / 20)-\operatorname{cosec}(180 / 40)] 2$

$=201.168($ approximated to 200$)$

$\mathrm{L}=\mathrm{pk}=1886.9 \mathrm{~mm}=1.88 \mathrm{~m}$ (Length of chain)

5)Fifthly calculating the staging with the Gear ratio as 2 approximately:

6 sets of Sprockets.

$\mathrm{N} 1=80 \mathrm{rpm}, \mathrm{N} 2=160 \mathrm{rpm}$

$\mathrm{N} 2=160 \mathrm{rpm}, \mathrm{N} 3=320 \mathrm{rpm}$

N3=320rpm,N4=640rpm

N5=640rpm,N6=1280rpm

$\mathrm{N} 7=1280 \mathrm{rpm}, \mathrm{N} 8=2560 \mathrm{rpm}$

$\mathrm{N} 8=2560 \mathrm{rpm}, \mathrm{N} 9=5120 \mathrm{rpm}$

6) Designing of flywheel for storage of energy:

$\mathrm{Cs}=0.02$ (coefficient of fluctuation of speed), $\mathrm{k}=1.8 \mathrm{~m}$ (radius of gyration), $\mathrm{m}=1.5 \mathrm{kgs}, \mathrm{I}=\mathrm{mk} 2=4.86 \mathrm{kgm} 2$

Energy stored in Flywheel: $\Delta \mathrm{E}=\mathrm{I} *(2 \pi \mathrm{N} / 60)[(2 \pi \mathrm{N} 1 / 60)$ -

$(2 \pi \mathrm{N} 2 / 60)]=1065.91 \mathrm{~J}$
$\Delta \mathrm{E}=\mathrm{mk}^{2} \omega^{2}$

from which, $\mathrm{m}=1.15 \mathrm{kgs}$

$\sigma=7 * 106 \mathrm{~Pa}$ (Limiting value of safe centrifugal force)

Material density $=7200 \mathrm{~kg} / \mathrm{m}^{3}$

$\sigma=\rho v^{2}$

$\mathrm{v}=31.2 \mathrm{~m} / \mathrm{s}$ (peripheral velocity)

$\mathrm{v}=(\pi \mathrm{DN}) / 60$, taking $\mathrm{N}=1800 \mathrm{rpm}$,

$\Rightarrow \mathrm{D}=0.331 \mathrm{~m}$ (diameter of the flywheel)

$\mathrm{v}=31.2 \mathrm{~m} / \mathrm{s}$ (peripheral velocity)

$\mathrm{v}=(\pi \mathrm{DN}) / 60$, taking $\mathrm{N}=1800 \mathrm{rpm}$,

$\Rightarrow \mathrm{D}=0.331 \mathrm{~m}$ (diameter of the flywheel)

7)Lastly we design shafts and bearings to mount the sprockets. Shaft of length of $20 \mathrm{~cm}$ is used of diameter $15.5 \mathrm{~mm}$

The bearing length is calculated to be $15 \mathrm{~mm}$ inner diameter.

8)After which designing was using CREO software:
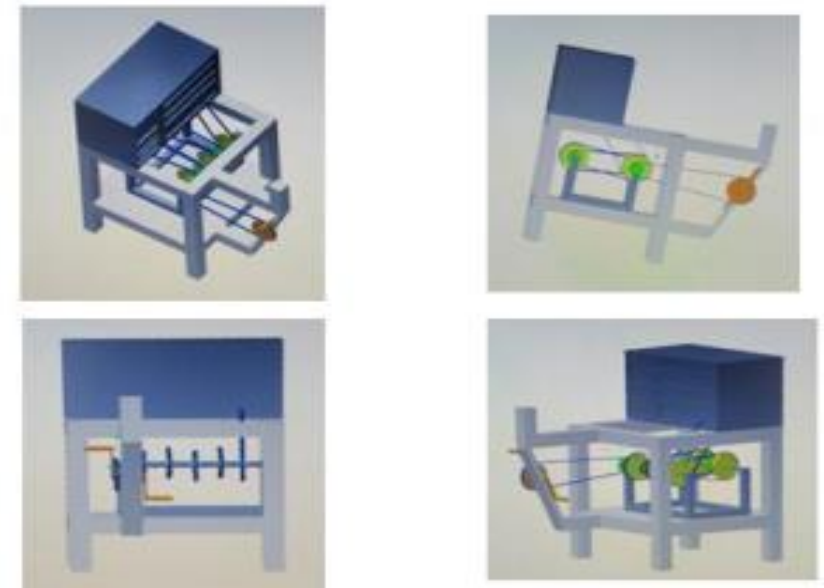

Fig 2.1 Isometric view of the model

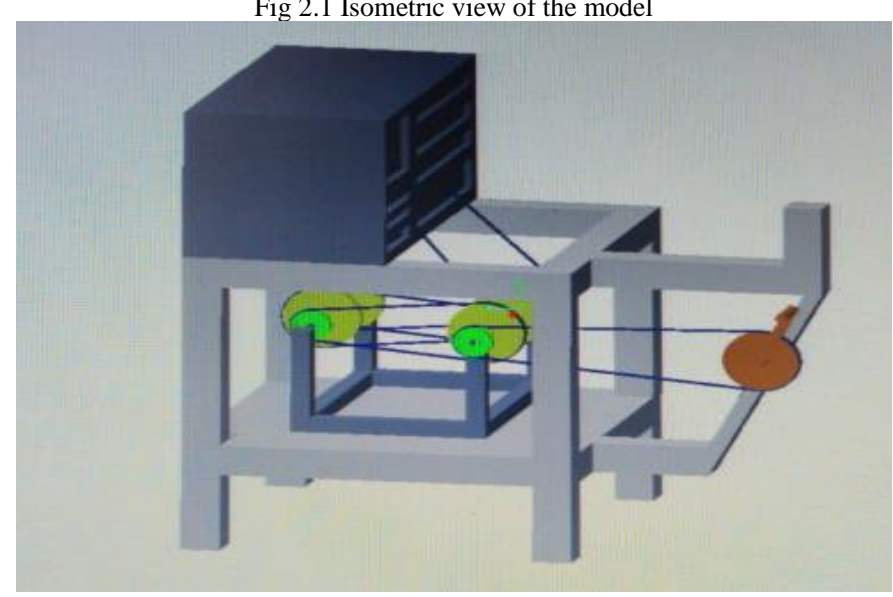

Fig 2.2 3-D model 


\section{FABRICATION:}

1)Firstly we started with procuring components which are readily available in the market, to start with we purchased sprockets which are used for the normal old style bicycle of 44 teeth sprocket (6 nos)

2)Then the small free wheel was purchased without the ball bearing and the inner bush was designed along with the keyway in order to hold it on the shaft and done in the lathe(6 nos). The free wheel had 16 teeth and the inner bush was done using mild steel.

3)The inner bush was then welded with the free wheel to be held on the outer sprocket.TIG welding was used to weld the material.

4)Then a shaft of inner diameter of $15.5 \mathrm{~mm}$ was fabricated to hold the two sprockets, along with the keyway along the full length of the shaft.The keyway of dimensions $5 * 2.5$ $\mathrm{mm}(6$ nos $)$,

5)Then the bearing with the housing of $15 \mathrm{~mm}$ inner diameter was available in the market and was purchased with a count of two per each shaft (12 nos).

6)Then the outer housing was fabricated in $38.1 * 38.1 \mathrm{~mm}$ pipe in mild steel material with a dimensions of $610 * 1220 * 770 \mathrm{~mm}$.

7)The rotary compressor of a window AC was opened by a cutter, the stator and the rotor were removed.

8)Flywheel was fabricated to the calculated dimensions.

9)Then the sprockets were arranged as per the design and coupled using a chain drive.

10)The flywheel output was given to the compressor for a constant operation of the air conditioner.

11)To make the cycling process more comfortable we add on the pedal and the seat for the passenger.

\section{RESULTS}

- The results that can be deduced from the above project for this specific paper can be the increase in rpm from 80rpm(nominal human pedalling speed)to 3600rpm (speed of the AC compressor in the no load condition).

- The flywheel is used to store energy and liberate it to achieve a constant output.

- The force applied by the cyclist was calculated to be $135 \mathrm{~N}$.

- The AC starts to run after a specified speed is reached and this is when the flywheel reaches a certain speed. This time is recorded.

\section{CONCLUSIONS}

\section{A. SUMMARY:}

The project was done in order to alleviate the problems faced in energy utilisation. The wastage of energy that is spent in the gym by the gymmers are converted into useful energy to run the air conditioner. This was done after going through a lot of literature survey and made an apt design for the best energy utilisation. This was one of the new approaches to operate AC by doing cycling motion which is completely mechanical.This makes the process more energy efficient.

\section{B. ADVANTAGES}

1. The main advantages is that the energy can be conserved and energy efficient.

2. The cost can be brought down in terms of the energy savings and cost of maintenance.

3. The motion is a simple pedalling motion.

4. The output is constant as we incorporate a specially designed flywheel.

5. The transmission is done with minimal loss of power as we use a chain drive.

\section{SHORTCOMINGS IN THE PROJECT}

1. The weight of the complete system is high and hence transportation is difficult

2. Incorporating this in an already existing spin bike is difficult.

3. The cost of initial construction is high.

4. Efficiency is less when compared to the electrically operated system.

\section{FUTURE SCOPE OF THE PROJECT}

This is a baby step in this research project of manually operated AC. There are various places that are left unattended, few of which are listed down.

1. The efficiency of the AC should be improvised.

2. The size and weight should be decreased and easily attachable to the existing spin bike.

3. This type of energy tapping can also be done for other gym equipment with reciprocating motions.

4. This can also be done for other types of air conditioners like split, ductless, portable AC etc..

- The AC runs constantly during the cycling motion. 


\section{ACKNOWLEDGMENT}

With a deep sense of gratitude we thank the God Almighty for giving us the strength and courage during the project work. We are also grateful to the faculty of the Department Of Mechanical Engineering of the Loyola Icam College of Engineering And Technology

\section{REFERENCES}

[1] R.S. Kurmi, "Theory Of Machines\|

[2] S.Md.Jalaludeen,\|Machine Design(volume-I)\|

[3] Gym Power Station: Turning Workout into Electricity- Mrs. Saylee Bidwai, Miss. Amruta Jaykar, Miss. Shivani Shinde, Miss. Snehal shindee-ISSN: 2395 -0056

[4] Power Generation Using Gym Equipment-Avinash Bhandari, Shailesh Itte, Jas Jangipuria, Ramesh Harayanp-ISSN: 2395-0072

[5] Electric Power Generation from Gym Equipment with Polarity Checker and Changer Circuit-V. S. Bonde B. V. Khatake D. V. Zambare,V. D. Patel,N. V. Kadam ISSN (online): 2321-0613

[6] Energy Harvesting from Gym Equipments-Madhup Kumar1, Dr. G S Mundada ISSN: 2347-653

[7] Gym Power Generation - Naimeesh CHM Shreedhar Kamatar ISSN (Online) 2321 